\title{
Determinants of Corporate Social Responsibility Practice of Manufacturing Firms in Dire Dawa Administration
}

\author{
Aschalew Mulugeta $^{1} \quad$ Hassen Muhammednur ${ }^{2}$
}

\begin{abstract}
The objective of this research is to find out determinants of corporate social responsibilities (CSR) of mineral water bottling companies in Dire Dawa Administration. Eight water bottlers in the city and four stakeholder organizations were included in the study. Primary data was collected from 308 sample of water bottling companies and 4 managers of the stakeholder organizations. Logit regression model was used to analyze the data with the help of SPSS version 20. The finding of the research showed that community pressure (CP), labour pressure (LP), customer demand (CD) and social license to operate (SL) are significant determinants of CSR, while sustainability practice (SU) is not significant determinant of CSR practice. The study recommended companies should practice CSR that accommodate the interested and influential stakeholder namely community, employee and customers.

Keywords: corporate social responsibility (CSR), Dire Dawa Administration, mineral water bottling company, determinants.
\end{abstract}

DOI: $10.7176 / \mathrm{DCS} / 10-6-04$

Publication date:June $30^{\text {th }} 2020$

\section{INTRODUCTION}

\subsection{Background of the Study}

The world is changing faster than ever before. Human numbers are growing faster, and the impact of human activities is being felt in more and more ways. This change has profound implications for business, and the world of Corporate Social Responsibility (CSR) is at the frontline of this change. So, it's worth looking for what are the current trends and where are they heading in the future.

Mallen Baker(2016) discussed Corporate Social Responsibility (CSR) as the continuing commitment by business to behave ethically and contribute to economic development while improving the quality of life of the workforce and their families as well as of the local community and society at large. Attitudes to business and its relationship with society are changed and shaped largely by outside events. These are demonstrations of social problems that change the environment within which companies do business, which are partially or wholly caused by business activities.

The practice of CSR is at its early stage in developing countries like Ethiopia. CSR as idea is new in ( (Kassaye ,2016)Described ,Ethiopia and started off by multinationals and NGOs to remedy the effects of their business activities on the local communities. Almost all of national companies and government organizations have not developed a concept CSR. However, some of Ethiopian companies have a tradition of partnership and dialogue with their communities and stakeholders in the form informal CSR practices ( Kassaye ,2016).

Research by Biznews Asia, (2010) indicated about $91 \%$ of the CEO's believed that society has placed far higher expectations from business today to take public responsibilities than it was five years ago; and about $61 \%$ of them also believed that this expectation will rise further in the next five years.

Ethiopia is one of the developing countries where the philosophy of corporate social responsibility is not well developed and also the governance system takes the form of mere control and decision making rather than encouraging development and implementation of a well developed ethical code of conduct. However, currently there are some good starts by some industries like the Ethiopian horticulture Association, who has been developed its own code of practice for its specific horticulture industry (Tedla Zegeye,2013).

The philosophy of CSR is basically to give back to society, what the business has taken from the society in the course of its action for creation of wealth.(Ghoshal and Moran, 1996). Companies who fail to recognize this CSR concept and not respond appropriately will put at risk not only their bottom line, but their very survival.

Salini s. et al.( 2011 ) discussed the analysis of shifting trend of CSR in relation to focus, paradigm and methodology. He found that there is also a shift in meaning, definition, and models of CSR regarding determinants of CSR initiatives, impact of CSR on both stakeholders and financial performance.

According to the detailed information about industries in Ethiopia accessed from www.ethiochamber.com, there are 1,773 medium and large scale industries are in operation throughout the country. According to Dire Dawa trade and investment office manufacturing sectors information,currently, there are 145 small scale, 94 medium scale and 9 higher scale manufacturing firms in Dire Dawa. Currently there are 67 water bottling companies in Ethiopia of which the majority are located in Oromia Region close to Addis Ababa where they can access the biggest

\footnotetext{
${ }^{1}$ Ass. professor of Management (RVU-DD campus)

${ }^{2} \mathrm{MBA}$
} 
number of consumers in the country, out of which 7 are located in Dire Dawa. But there is still huge gap between demand and supply. Therefore, in the future, many new entrants in the industry will be expected to join the water bottling business.

According to the report by the 'life without plastic initiatives', Plastic packaging (in our case mostly plastic water bottles) is significant source of landfill waste and is regularly eaten by numerous marine and land animals, to fatal consequences.

Environmentally, plastic is a growing disaster. Most plastics are made from petroleum or natural gas; nonrenewable resources extracted and processed using energy-intensive techniques that destroy fragile ecosystems. The manufacture of plastic, as well as its destruction by incineration, pollutes air, land and water and exposes workers to toxic chemicals, including carcinogens. The surprising part of study in UK is that plastic wastes degradability year is not certainly known because plastics are come to production since the last 70 years. Plastic waste persisted without decaying for decades and probably persists for centuries, if not millennium. In the case of Water Bottlers in Dire Dawa administration, it is very crucial to integrate Corporate Social Responsibility practices in to their business strategy to manage the health and environmental problems caused by plastic bottles thrown away after usage.

\subsection{Statement of the problem}

Back to the last few decades there has been a growing public awareness of the role of corporations in society. Is profit the only concern of corporations? Or do other social and environmental concerns play a role as well? Not only these questions became commonplace at the business table and business press, but also vast body of academic literature emerged around these questions (Margolis \& Walsh, 2003).

Stefan Bruns, 2017,during his emherical study under the topic The determinants of corporate social responsibility: empirical evidence from the Netherlands, he outlined and explained several factors that could drive CSR. (Stefan Bruns, 2017) categorized these factors under three categories and summarized as institutional or industry characteristics, firm characteristics, or corporate governance characteristics.

Multiple studies have also investigated various determinants of CSR and provided evidence that CSR is a multi-dimensional construct with determinants that have different characteristics (Gamerschlag et al., 2010; Reverte, 2009; Padgett \& Galan, 2010; Artiach et al., 2010). Over the years, it has become clear that determinants of CSR either have certain institutional or industry characteristics, firm characteristics, or corporate governance characteristics (Stefan Bruns, 2017).

According to www.mining.com(2016) and many other media coverage, current practices in Ethiopia shows large scale companies such as MIDROC Gold Mining and SHER Ethiopia(the largest floriculture company located around Zeway lake)and many other companies are threatened for their future survival ; because they lose social license from the community in which they operate their business. The community started to enforce organizations so that the organizations should operate in a socially responsible manner and towards the fulfillment of at least the three bottom line of CSR, namely people, planet and profit. This indicates even large firms should identify and engage in CSR practice to assure their existence.

Inorder to identify determinant of CSR, Martin M. and Yunita A. (2012), studied "Impact of Corporate Social Responsibility toward Firm Value and Profitability". The finding showed profitability is one of CSR practice determinant factor. And on the basis of descriptions about determinants of CSR, Nick C. (et al, 2010) discussed 45 Forces of Driving Corporate Social Responsibility.

Based on Nick C. (et al, 2010) "45 Forces Driving Corporate Social Responsibility" the findings of CSR determinants are summarized as follows:

More than ever before, community is placing social, ethical and environmental expectations on organizations large and small. Many companies are now engaging in corporate social responsibility to catch up with these expectations.

Shareholder resolutions related to social and environmental issues have steadily increased year-on-year. Through these resolutions, activist investors attempt to sway management policies either by passing a binding resolution or simply by forcing the board and senior management to respond to social concerns.

Indeed, these days ,employees at all levels are suffering from lack of meaning at work. Even at the lowest levels of many companies, entrepreneurial employees are launching their own initiatives targeting social and environmental issues within the context of their company. So grassroots employee activism is the other critical determinant of the practice of CSR.

CSR and ethics education is the other determinant of CSR practices. In response to the growing interest in corporate social responsibility, companies are sending staff to workshops focused on sustainability, ethical decision making, and other dimensions of CSR. MBA programs worldwide are incorporating CSR into their curriculum.

The other determinant of CSR according to (Nick C. et al, 2010) finding is level of social license. In order for buyers to verify the social and environmental record of their suppliers, many are turning to certification programs 
that provide independent verification. ISO 14001 was one of the first and most popular of these programs, but many more have been launched afterwards such as ISO 26000.

The internet and social media is also affects CSR activity. Once, the internet enhanced the public's access to information - including information about social issues and environmental performance of companies. On Facebook, Twitter, thousands of review sites and tens of thousands of discussion forums, people's compliments, complaints, and criticisms are readily shared with the world.

Regulation on social and environmental reporting influences the company to be socially responsible. In a fairly recent development, some jurisdictions and laws are now pursuing legislation or securities regulation that would force companies to report on social and environmental performance, similar to mandatory financial reporting to shareholders (Nick C. et al, 2010).

The other very important factor is sustainability and profitability. One common myth of corporate social responsibility is that it is costly to implement. But on the contrary, many companies are being driven to engage in responsible business practices out of a desire to save money. Firms that conserve energy \& resources and create a more efficient value chain help the environment and their bottom line. Some companies are even earning revenue through their activities Ghoshal and Moran, 1996).

International organizations including NGOs put pressure on CSR practices. These organizations are engaged to raise public awareness of social issues and to pressure those with the power to fix those issues. This activism is responsible for much of the increase in public awareness of social issues and the questionable activities of some companies, as well as shifting attitudes toward the social role of the corporation.

Generally past empirical studied on determinants of CSR topics had the following gaps.

The studies did not investigate CSR practices in accordance with the five determinants in this study. In addition to this, greater number of studies focused only on quantitative dimensions of CSR determinants.

Former studies related to CSR did not concentrated specifically on Drinking water manufacturers

The former studies methodologies were based on questionnaires and interviews as instrument for data Collection mainly from managers and employee, although, the community is the source of primary information especially related to environmental matters.

Because of the dynamic nature of CSR, Papers conducted under CSR heading showed dynamic shifting trend in relation to focus, methodology, etc which indicates the need for frequent revision of research papers.

\subsection{Research Questions}

At the end of the research, the study has tried to answer the following research questions:

What are the determinants of CSR practices of Drinking Water Bottlers in Dire Dawa administration?

To what extent does CSR practice in Drinking water Bottler firms in Dire Dawa administration is effective?

What are the challenges that CSR practices among Drinking water Bottlers in $\mathrm{n}$ Dire Dawa administration is experiencing?

Do the concerned stakeholders in water bottling companies work together towards CSR practices?

\subsection{Research objective}

\subsubsection{General Objectives}

The general objective of this research is to examine the determinants of Corporate Social Responsibility (CSR) practice of drinking water manufacturing firms located in Dire Dawa Administration.

1.4.2 Specific Objective

The specific objectives of the study are to:

1. To find out whether water bottling companies under the study are influenced towards CSR because of Labour pressure, Customer demand, Community pressure, Sustainability and Social license.

2. Assess the extents of CSR practices among drinking Water companies located in dire Dawa Administration.

3. Find out the challenges faced by water bottler companies and stakeholders to practice CSR.

4. Assess the extent that stakeholders and water bottling companies in Dire Dawa Administration work together towards CSR practices.

\subsection{Significance of the study}

The findings of this research are of great help and important to various groups. It helps the top management in the manufacturing industries to understand needs and demands of the society in which they operate thire business in. This intern plays a major role in influencing the nature of strategic planning trend, allocation of resource, formulation of company policies, marketing activities and other aspects of business.

The government and company policy makers utilize the findings for new policy consideration especially to the environmental concern and sustainability, and this will enable them establish a new strategy for promoting environmental protection through consumer protection, product safety and work place hygiene and recycling wastes. 
The stakeholders of the organizations including society at large will benefit significantly in terms of information provided on CSR, knowledge and awareness of social issues, environmental safety, employment, health issues and other benefits in CSR.

Since CSR is at its infant stage in Ethiopia, the researcher believes this study helps other researchers as a source document and as a stepping stone for those researchers who want to make further study on the area afterwards.

\subsection{Scope of the Study}

Conceptually, the scope of the study is mainly related to investigating the CSR practices and CSR determinants of Drinking Water bottler. All organizations, for profit or not for profit, governmental or nongovernmental, need intensive effort on the area of corporate social responsibility to create good organizational and social environment. Geographically, the study will include Water bottler companies located in Dire Dawa Administration. Regarding determinants of CSR, only five predictors were selected for the research despite more many determinant variables can be available to research.

\subsection{Limitation of the Study}

Firstly, for the purpose of specialization, available time and resource constraints, this study focused only on corporate social responsibility practices of eight Mineral water manufacturing firms in Dire Dawa Administration, although CSR is equally important in all other industries. Therefore, because of the industry scale difference and specific nature of each manufacturing industries, the result of this study may not be used for generalization of all manufacturing firms.

Secondly, the limitation of this particular study is emerged from the concentration of the researcher mainly towards stakeholder theory, even though CSR concept is supported by a number of theories.

The third limitation of the study is that, the community has to include community members directly in the sample respondents because; real information can be extracted from the society. To moderate the effect of this limitation, four public and governmental organizations are used as a proxy of the community.

\section{REVIEW OF THE RELATED LITERATURE}

\subsection{Introduction}

This chapter deals with review of literature on "Corporate Social Responsibility (CSR)" under the background to assess determinants of CSR practices. The chapter begins with the Definitions and Concepts of CSR followed by the brief discussion on Challenges of CSR, and Reasons why firms engaged in CSR practices. Theoretical support of CSR by Stakeholder theory also discussed in this chapter. Indicators of CSR and Determinants of CSR including their respective empherical study is also part the chapter. Finally, Conceptual framework of the study is discussed in detail.

\subsection{Definitions and Concepts of CSR}

Many CSR definitions were developed by the scholars in the past, based on the social, economical, political and environmental context of that period since 1950s. Paul H. (2014), explained corporate social responsibility (CSR) is also known by a number of other names. These include corporate responsibility, corporate accountability, corporate ethics, corporate citizenship or stewardship, responsible entrepreneurship, are to name just a few. As CSR issues become increasingly integrated into modern business practices, there are trends towards referring to it as "responsible competitiveness" or "corporate sustainability." These concepts, however, are very general and they indicate only the other names of CSR. They didn't point out technical and practical definitions of CSR as (Shafiqur R. 2014) supposed that various definitions of CSR cover various dimensions including economic welfare, ethical practices, environmental protection, stakeholders' involvement, transparency, accountability, responsible behavior, moral obligation and corporate responsiveness.

Business for Social Responsibility (2003) definesd CSR as: Socially responsible business practices that strengthen corporate accountability, respecting ethical values and in the interests of all stakeholders. Responsible business practices respect and preserve the natural environment, helping to improve the quality and opportunities of life, and empower people and invest in communities where a business operates. The definitions of Global Corporate Social Responsibility Policies Project (2003) as well as World Business Council for Sustainable Development are also very similar with the definitions of Business for Social Responsibility.

Hopkins M. (2011), in his concept of Corporate Social Responsibility, Corporate Social Responsibility was concerned with treating the stakeholders of a company or institution ethically or in a responsible manner. That means treating key stakeholders in a manner deemed acceptable according to international norms. This definition is highly broad and focused on stakeholders of a company.

European Commission (2012) describes CSR as close relationships between companies and societies to tackle social and environmental concerns. They define CSR as a concept whereby companies integrate social and 
environmental concerns in their business strategy and operations and in their interaction with their stakeholders on a voluntary basis. In its new Communication on CSR, the Commission puts forward a new definition of CSR: "the responsibility of enterprises for their impacts on society."

The Commission then states that: "To fully meet their corporate social responsibility, enterprises should have to integrate social, environmental, and ethical and human rights concerns into their business operations and core strategy in close collaboration with their stakeholders" (New EU definition on CSR mirrors Enterprise 2020 aspirations -(2012). These definitions more or less describe CSR as whole. However, the definitions tie CSR only with business operations and strategies. CSR practices should be treated beyond business operations and strategies. Although CSR sometimes is obligatory, the European Commission definitions and others limit it as a voluntary activity.

Different meanings in a variety of contexts are raised about the definition of CSR by diverse Academic scholars and researchers. But, the above definitions more or less included these varieties of concepts on CSR. Meanwhile, as a reference to this study, CSR can be defined as a voluntary as well as obligatory activity of a business or an institution towards labor treatment, consumer protection, community welfare, environmental protection, human rights, transparency and anti-corruption, health and quality of life to enhance economical, social, political, ethical and environmental standards of the society as a whole (Caroll,1995) .

\subsection{Indicators of CSR practices}

CSR practices and determinants can be described based on ISO 26000 seven fundamental subjects of CSR which are supported by lots of research findings on CSR (Jones ,1999). These CSR standards are environment, labor practice, human rights, organizational governance, fair operating practice, consumer issues and social development (Matiyas ,2016). Therefore, on the basis of these standards, empirical studies of CSR indicators are summarized and presented below including CSR determinants.

\subsection{Determinants of CSR}

Different CSR determinants were collected by (Stefan Bruns, 2017) during his emherical study under the topic The determinants of corporate social responsibility: empirical evidence from the Netherlands, he outlined and explained several factors that could drive CSR. (Stefan Bruns, 2017) categorized these factors under three categories and summarized as institutional or industry characteristics, firm characteristics, or corporate governance characteristics.

Factors, which decisively affect the nature or outcome of CSR, are known as determinants of CSR (Reverte, 2009). Multiple studies have investigated various determinants of CSR and provided evidence that CSR is a multidimensional construct with determinants that have different characteristics (Gamerschlag et al., 2010; Reverte, 2009; Padgett \& Galan, 2010; Artiach et al., 2010). Over the years, it has become clear that determinants of CSR either have certain institutional or industry characteristics, firm characteristics, or corporate governance characteristics

\subsection{Conceptual Framework}

By combining institutional or industry characteristics determinants emphrical evidences and ISO 26000 concepts,Five determinants of CSR practices are identified and used as independent variable while the dependet variable is CSR practice of companies. 


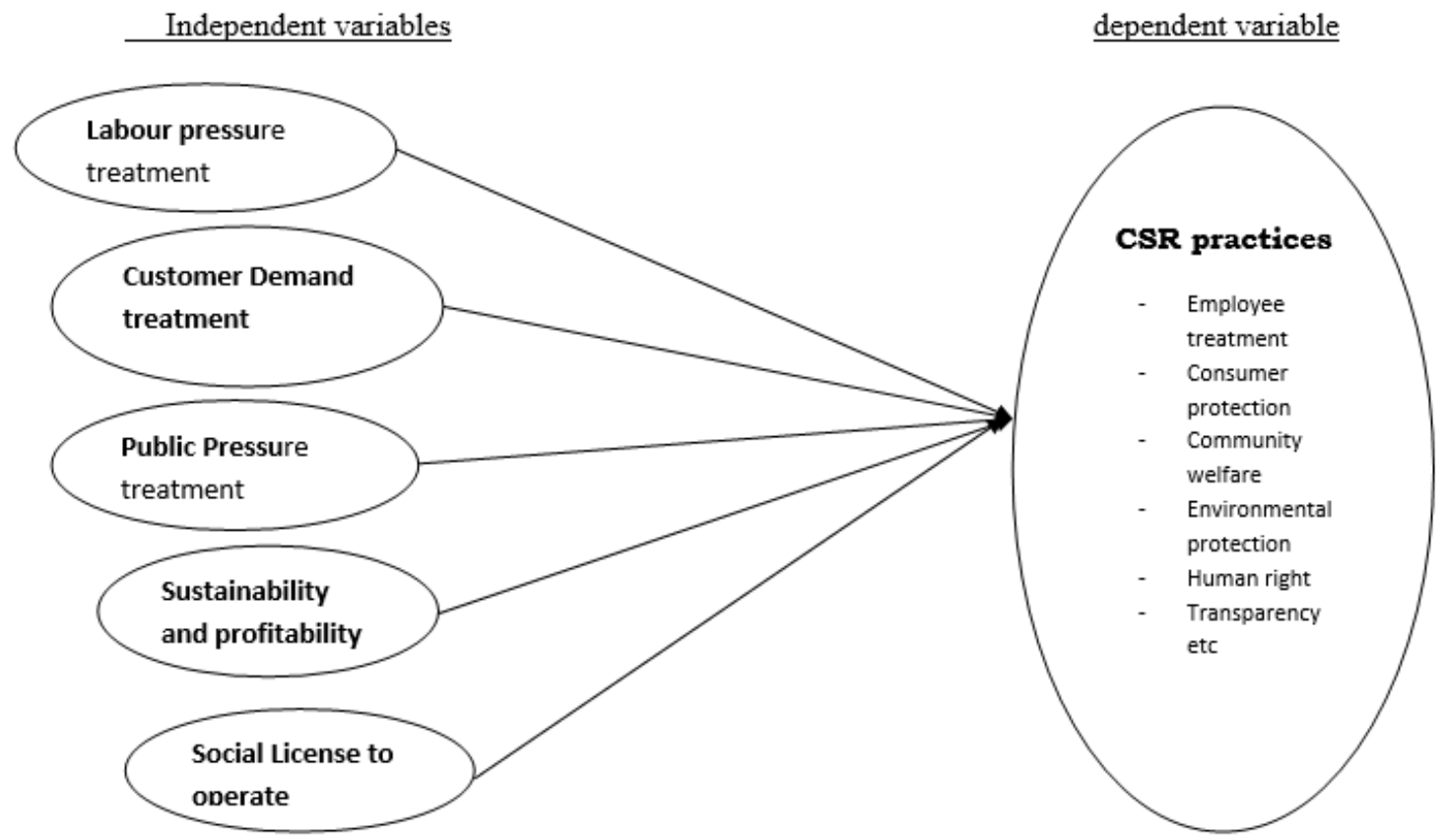

Figure 2.4. Conceptual Framework of the Study

\section{RESEARCH METHODOLOGY}

\subsection{Introduction}

This part of the study briefly discussed about the research design applied for the study and how the research is conducted. Therefore, this chapter attempt to describe the research design, unit of analysis, sampling design, sources of data, methods of data collection and instruments, method of data analysis, and specifying the model.

\subsection{Research Design}

The study applies survey research technique in which a sample is interviewed in order to describe the perception of respondents. In addition, secondary data analysis method of descriptive research design was also selected for the study.

Surveys are non-experimental designs that do not involve controlling or manipulating independent variables.

The study have been conducted based on mixed research method with the development and perceived legitimacy of both qualitative and quantitative research approaches which employs the data collection associated with both forms ,primary and secondary data, to capture the best of both quantitative and qualitative approaches but with emphasis of quantitative approaches.

The reason behind to select this approach was to integrate findings from different data sources. In addition to this, the reason why a mixed method design employed was to expand an understanding from one method to another, to converge or confirm findings from different data sources by triangulation. Both the quantitative and qualitative data were collected in phases, sequentially. Thus, when the data are collected, the quantitative data came first then followed by the qualitative data as designed in questionnaires. Consequently, the priority (domination) has been skewed toward quantitative data. Therefore, these two types of data were integrated at stage of data analysis and interpretation.

Data collection tools of the study were questionnaires and interview. Mixed methods research, then, is more than simply collecting qualitative data from interviews, or collecting multiple forms of qualitative evidence or multiple types of quantitative evidence. Questionnaire was the main instrument of this study. Questionnaire items designed from different sources have been developed for this study particularly. The questionnaire are designed to encompass two sections: the first part of the questionnaire is about the practices of CSR (the dependent variable. questions were prepared concerning six standards of CSR practices based on ISO 26000). The second part of the questionnaire was about the independent variables of the study. It included questions regarding the five independent variables. The structured and closed ended questionnaires are conducted with the sample respondents at their destination.

Structured and unstructured interview have been also conducted with managers of the respected companies and representatives of the community through open ended questions which have been designed to elicit their understanding about the nature of CSR and determinants of CSR and challenges of CSR practices in their respective organization. Eight mineral water company managers and four governmental and community agency 
managers were interviewed as proxy of detecting social attitudes regarding CSR practices and determinants. Dire dawa Adminstration Trade Industry and Investment Agency, Dire dawa Adminstration Beutification Agency, Environmental, Forest and Air protection Authority(EFAA), the former EPA and Private Organization Employee Social Security Agency(POESSA),Dire Dawa branch were the four organizations included under the study.

\subsection{Sources of Data}

Sources of data for the study include both primary and secondary data. The study had begun with secondary data analysis of the case through the detailed review of related literature. In this regard, the researcher had refer different books, published and unpublished documents, journals, articles and research papers to get information on theoretical and empirical frame work of the study. The primary data have been collected from employees, managers of companies and community representatives through questionnaires and interview.

\subsection{Sample Design}

Major issues under this section are searching answer of question how to select the sampling units. Who is to be sampled?, how big should the sample be? and how to select the sampling units?

\subsubsection{Target Population}

Related to the study, the target population is the current management and non- management staff members of all eight Water bottling companies in Dire Dawa Administration. Those governmental and non-governmental organizations and stakeholders who have direct influence on water bottlers are included. Environmental,Forest and Air pollution Protection Agency(EFAPA), The city Manicipality office, Trade, Industryand Investment office (TIIA) are those stake holders included in the study.These organizations were included in the study because they regulate and license the water bottler companies. They can also reflect the community interest on those companies included in the study. Generally, all 1200 staff members of water bottling firms and managers of the listed stakeholders organizations are included in this study as target population.

3.4.2. Sampling Technique and Sample Size Determination

There are several approaches to determine the sample size. These include using a census for small populations, imitating a sample size of similar studies, using published tables, and applying formulas to calculate a sample size. This study applied a simplified formula provided by Yamane (1967) to determine the required sample size at $95 \%$ confidence level, degree of variability $=0.5$ and level of precision $=5 \%$

Where:

$$
n=\frac{N}{1+N(\mathrm{e})^{2}}
$$

$\mathrm{n}=$ the sample size

$\mathrm{N}=$ the population size

$\mathrm{e}=$ the level of precision or sampling error $(0.05)$

Accordingly, the sample size for non-managerial staff is calculated as follow.

$$
n=\frac{1200}{1+1200(0.05)^{2}}
$$

$\mathrm{n}=300$

The calculated respondent sample from all companies as per the above formula is again proportionately distributed among selected companies. The average non-manager staff of water bottlers companies under the study is found to be 150 heads. Proportionate distribution of the calculated 300 respondents among 8 companies is equal to 38 respondents per company.Using simple random probability method, 38 respondents were selected from each company. Each of managers from four public organizations namely;Dire dawa Adminstration Trade and Industry investment office,Dire dawa Adminstration Beutification Agency,Environmental,Forest and Air pollution Authority(EFAA), the formerEPA and Private organization employee social security agency are selected purposely.By the same procedure managers of eight water bottlers copany are included in the sample. Totally 312 respondents were participated for this study. 
Table 3.1 Samle size determination

\begin{tabular}{|c|c|c|c|c|c|c|c|c|c|c|}
\hline \multirow{2}{*}{$\begin{array}{l}\text { Respon } \\
\text { dent's } \\
\text { profile }\end{array}$} & \multicolumn{2}{|c|}{ Sampling Frame } & \multicolumn{2}{|c|}{ Sample size } & \multicolumn{2}{|c|}{$\begin{array}{l}\text { Proportion } \\
\text { organization }\end{array}$} & \multicolumn{2}{|c|}{$\begin{array}{l}\text { Sampling } \\
\text { method }\end{array}$} & \multicolumn{2}{|c|}{ Total sample } \\
\hline & $\begin{array}{l}\text { Water } \\
\text { comp } \\
\text { anies }\end{array}$ & $\begin{array}{l}\text { Public } \\
\text { organiz } \\
\text { ations }\end{array}$ & $\begin{array}{l}\text { Water } \\
\text { comp } \\
\text { anies }\end{array}$ & $\begin{array}{l}\text { Public } \\
\text { organiz } \\
\text { ations }\end{array}$ & $\begin{array}{l}\text { Water } \\
\text { comp } \\
\text { anies }\end{array}$ & $\begin{array}{l}\text { Publiorgan } \\
\text { izations }\end{array}$ & $\begin{array}{l}\text { Water } \\
\text { comp } \\
\text { anies }\end{array}$ & $\begin{array}{l}\text { Public } \\
\text { organiz } \\
\text { ations }\end{array}$ & $\begin{array}{l}\text { Water } \\
\text { comp } \\
\text { anies }\end{array}$ & $\begin{array}{l}\text { Public } \\
\text { organiz } \\
\text { ations }\end{array}$ \\
\hline $\begin{array}{l}\text { Manage } \\
\text { rs }\end{array}$ & 8 & 4 & 8 & 4 & 8 & 1 & $\begin{array}{l}\text { Non- } \\
\text { proba } \\
\text { blity }\end{array}$ & $\begin{array}{l}\text { Non- } \\
\text { probabl } \\
\text { ity }\end{array}$ & \multirow[t]{2}{*}{308} & \multirow[t]{2}{*}{4} \\
\hline $\begin{array}{l}\text { Non- } \\
\text { manage } \\
\text { rs }\end{array}$ & 1200 & - & 300 & - & 38 & - & $\begin{array}{l}\text { Simpl } \\
\text { e } \\
\text { rando } \\
\mathrm{m}\end{array}$ & - & & \\
\hline \multicolumn{9}{|c|}{ Total respondent } & \multicolumn{2}{|l|}{312} \\
\hline
\end{tabular}

\subsection{Methods of Data Analysis}

Analysis occurs both within the quantitative (descriptive and inferential numeric analysis) approach and the qualitative approach, and often between the two approaches (Creswell et al. 2003).

After data collection is completed, it was edited in order to identify errors and omissions and correct them when needed. Then, the edited data was coded and classified. All these activities was carry out to make the data reliable and can be easily calculated for analysis and generate meaningful output based on Statistical Package for Social Science (SPSS) Version.20.

According to Junqi Lin (2012) Five point Likert scale is being one of the most reliable measurement scales and popular. The researcher applied Five point Likert scale on questionairs for this study. Respondents were asked to scale their perception as strongly agree, agree, neutral, disagree, or strongly disagree and the agreement level of respondent is coded 5-1 respectivily. Interval with five-point scale is calculated using the following formula:(5-1) $/ 5=0.8$

Based on the above calculation, the scores fall between the ranges of:

4.21-5.00 were considered as Strongly agree

3.41-4.20 were considered as Agree.

2.61- 3.40 were considered Neutral.

1.81- 2.60 were considered Disagree.

1.00-1.80 were considered as strongly disagree

But for the sake of conclusion comfortability, the above scales are diminished to three scales namely; Agree(3.51 and above),Neutral(2.51-3.50) and Disagree (below 2.51).Finally, the results of the interview with managers and stakeholder organization had integrated to the responses of employees and have been analyzed accordingly.

The positive reactions the companies exerted to responded the external and internal stakeholders is used to measure the independent variables using their mean from score of five point likert scale measurement and analyzed whether these constructs are determinants of CSR practice. Labour pressure, customer demand, community pressure, sustainability issue and social license (legitimacy) are the independent variables used for the study

\subsection{Research Model Specification}

In models where the dependent variable is qualitative, the objective is finding the probability that something happening. Hence, qualitative response regression models are often known as probability models is used to find the probability CSR occurrence and other related statistics results . There are three approaches to developing a probability model for a binary response variable: the linear probability model (LPM), logit model and probit model (Gujaratti,1996)

This research used logit model among the above probability models because the regressand is a binary, or dichotomous variable. The fundamental problem with the LPM,among probability models is that it is not logically a very attractive model because it assumes that $\mathrm{Pi}=\mathrm{E}(\mathrm{Y}=1 \mid \mathrm{X})$ increases linearly with $\mathrm{X}$, that is, the marginal or incremental effect of $\mathrm{X}$ remains constant throughout. The logit model is selected over LPM because logit and probit models solved the fundamental problem LPM has.

The LPM

$$
\mathrm{Pi}=\mathrm{E}(\mathrm{Y}=1 \mid \mathrm{Xi})=\beta 1+\beta 2 \mathrm{Xi}
$$




$$
P_{i}=E\left(Y=1 \mid X_{i}\right)=\frac{1}{1+e^{-\left(\beta_{1}+\beta_{2} X_{i}\right)}}
$$

The above equation can be written as:

$$
P_{i}=\frac{1}{1+e^{-Z_{i}}}=\frac{e^{z}}{1+e^{z}}
$$

where $Z_{i}=\beta_{1}+\beta_{2} X_{i}$.

Therefore, we can write

$$
\frac{P_{i}}{1-P_{i}}=\frac{1+e^{Z_{i}}}{1+e^{-Z_{i}}}=e^{Z_{i}}
$$

$\mathrm{Pi} /(1-\mathrm{Pi})$ is simply the odds ratio - the ratio of the probability something will occur to the probability that it will not occur.(Gujarati,2003).

$$
\begin{aligned}
L_{i}=\ln \left(\frac{P_{i}}{1-P_{i}}\right) & =Z_{i} \\
& =\beta_{1}+\beta_{2} X_{i}
\end{aligned}
$$

$\mathrm{Li}$ is the $\log$ of the odds ratio, is not only linear in $\mathrm{X}$, but also linear in the parameters. $\mathrm{L}$ is called the logit, and hence the name logit model. Although we have included only a single X variable, or regressor, in the preceding model, one can add as many regressors as may be dictated by the underlying theory.

Hence, specific to this research, CSR practice is dependent variable, where as five independent variables are considered; namely, Labour pressure (LP), Customer demand (CD), Community pressure(CP), and Sustainability $(\mathrm{Su})$ and social license to operate(SL).Hence the model can be formulated as follows.

$\mathrm{P}(\mathrm{CSR})=\ln \left(\frac{p}{1-p}\right)$

$\mathrm{P}(\mathrm{CSR})=\frac{1}{\left.1+e^{-(\beta o+\beta} 1 L P+\beta 2 C D+\beta 3 C p+\beta 4 S U+\beta 5 S L\right)}$

Where: $\mathrm{P}(\mathrm{CSR})$ is probability of CSR practice, LP is Labuor pressur, $(\mathrm{CP})$ is Customer demand $(\mathrm{Cp})$ is Community pressure, $(\mathrm{Su})$-Sustainability and (SL) is social license to operate.

\subsection{Evaluating the Research Measurements}

\subsubsection{Reliability}

A measure is reliable when different attempts at measuring something converge to the same result. So, the concept of reliability revolves around consistency (William G.Zikmund, etal 1998). Coefficient alpha $(\alpha)$ is the most commonly applied estimate of a multiple-item scale's reliability. It represents internal consistency by computing the average of all possible split-half reliabilities for a multiple-item scale. Among different methods of measuring reliability, a Cronbacha's alpha $(\alpha)$ coefficient is applied for this study. The five instruments selected as determinants of CSR; labour pressure, customer pressure, community pressure, sustainability and social license to operate are tested for reliability on data collected from 20 volunteer respondents. The SPSS result shows Cronbacha's alpha $(\alpha)$ coefficient is 0.76 . According to William G. Zikmund(1998), a coefficient $(\alpha)$ between 0.80 and 0.95 are considered to have very good reliability. Scales with a coefficient $(\alpha)$ between 0.70 and 0.80 are considered to have good reliability; and an $(\alpha)$ value between 0.60 and 0.70 indicates fair reliability. When the coefficient is $(\alpha)$ below 0.6 , the scale has poor reliability. Therefore the pilot test confirms the measure is reliable, since Cronbacha's alpha $(\alpha)$ coefficient is 0.76 . The alpha $(\alpha)$ coefficient between indicators of each construct is summarized using the table.

3.7.2 Validity

Validity is the accuracy of a measure or the extent to which a score truthfully represents a concept (Creswell, 2009). It is how we accurately measuring what we think we are measuring? The four basic approaches to establishing validity are face validity, content validity, criterion validity, and construct validity (WilliamG.Zikmund, etal 1998).

Validity of this study is achieved through intensive discussion with professionals and reaching subjective agreement that a scale logically reflects the concepts being measured in the study. Its criterion validity, the ability of a measure to correlate with other standard measures of similar constructs is checked to ensure how well the measure works in practice. To check Whether or not the measures cover the domain of interest and capture the entire scope of the study, a detail discussion and comment was collected from references and professionals and used to adjust the measures so that its content validity can be ensured. Convergent validity was tested to ensure the acceptable relationships amongst indicators in the same construct. Convergent validity shows the degree to 
which the items of a construct are related, and it is assessed by examining the correlation between the indicators to ensure reasonable relationship between items in the same construct. Additionally, Amharic version of the questionnaire is distributed for those respondent who cannot understand English language adequately.

\section{Results and Discussions}

\subsection{Respondents profile}

Out of 312 distributed questionnaires, 300 were retuned back with complete data and among respondents involved in the study, 270 were male and 30 were female. In percentage 90 percent of the respondents were male 10 percent of the respondent were female. The unbalanced percentage of male over the female may be because of the nature of industries under the study. The nature of water bottling industry, to some level, is labour intensive that is more appropriate for males.

Table 4.1 showed 75 percent of the respondents age is categorized under the age below 35 years, only 25 percent of the respondents are fall under the age above 36. This testified majority of the labour force is under younger category. The same reason of industry nature, that is labour intensive nature, can be the case of majority younger employees in the water bottlers company.

About of 312 sample size,21 managers and 279 non-managers were involved in the study. The respondent profile also showed, $70 \%$ of the respondent's educational level is in the category of $6-12$ grade, $25 \%$ are fall under diploma and degree level and 5\% fall under above. Demographic profile of respondent is listed in table 4.1. below Table 4.1. Respondents' Demographic profile

\begin{tabular}{|c|c|c|c|c|}
\hline Variable & Value & Frequency & $\mathrm{N}$ & Percentage \\
\hline \multirow[t]{3}{*}{ Gender } & -Male & 270 & \multirow{3}{*}{300} & 90 \\
\hline & -Female & 30 & & 10 \\
\hline & Total & 300 & & 100 \\
\hline \multirow[t]{5}{*}{ Age in year } & $15-25$ & 90 & \multirow{5}{*}{300} & 30 \\
\hline & $26-35$ & 135 & & 45 \\
\hline & $36-45$ & 15 & & 20 \\
\hline & 46 and above & 60 & & 5 \\
\hline & Total & 300 & & 100 \\
\hline \multirow[t]{3}{*}{ Occupation } & -Manager & 21 & \multirow{3}{*}{300} & 7 \\
\hline & -Non-manager & 279 & & 93 \\
\hline & Total & 300 & & 100 \\
\hline \multirow[t]{5}{*}{ Education Level } & -Grade 6-11 & 210 & \multirow{5}{*}{300} & 70 \\
\hline & -College Diploma & 75 & & 25 \\
\hline & Degree & 15 & & 5 \\
\hline & -Above Degree & - & & - \\
\hline & Total & 300 & & 100 \\
\hline
\end{tabular}

\subsection{Estimation of the model}

This section discusses the result of estimation of the model based on SPSS results. In reference to our model specification in chapter 3 , the research model was designed to be regression, using the binary logit model where the dependent variable's occurrence probability is predicated by independent variable.

Therefore the probability of occurrence of CSR practice $(\mathrm{Y})$ in water bottling companies is explained by the independent variables (X) namely: labour pressure (LP), consumer demand (CD), community pressure (CP). Sustainability (SU), and social license to operate (SL).

The positive response water bottling companies exert to respond the listed external internal pressure is used to measure the value of independent variables through respondent's perception. In the preceding paragraphs the probability of occurrence of CSR practice is predicated by the independent variables of the study.

Based on the result of SPSS combined in table $4.2 \beta$ is the value to be replaced in the model to establish the probability, it is in the interpretation, by logistic regression is $\beta$ represents, the change associated with the dependent variable (CSR practice) because of one unit change in predictor variables, replacing in the equation.

$\mathrm{P}(\mathrm{CSR})=\beta_{0}+\beta, \mathrm{LP}+\beta_{2} \mathrm{CD}+\beta_{3} \mathrm{CP}+\beta \mathrm{sa}+\beta_{5} \mathrm{SL}+\mathrm{e}$

$\mathrm{P}(\mathrm{CSR})=\beta_{0}+1.80 \mathrm{LP}+1.74 \mathrm{CD}+2.17 \mathrm{CD}+1.1951+\mathrm{e}$

The odd ratio is described as (EXP)B in SPSS output table. If the value of (EXP)B is greater than 1, the increase in the predictor by one unit also increased the occurrence of the dependent value, if it's less than 1 it decreases the probability of occurrence of the predicted value.

As per the table 4.2, odds ratio, the values exp (B) are 6.02, 5.68, 8.76, 0.15 and 3.30 for labour pressure (LP), consumer demand (CD), community pressure (CU), sustainability practice (SU) and social license to operate (SL) respectively. Except the sustainability practice $(\mathrm{SU})$, the other odd ratio values are significant at $\mathrm{P}$ value $<0.05$, 
but sustainability $(\mathrm{SU})$ is significant at $\mathrm{P}$ value $<0.10 . \beta$ values tha shows the occurrence frequency of CSR practice is positive except for sustainability practice.

The result told us, due to the labour pressure (LP) increment by one unit as a predictor, the independent variable, CSR practice, is increased by a multiple of 6.02.It showed Labour pressure such as employee activism, is one of the CSR practice determinants.

The result is supported by previous empherical finding. For example research paper by (warsi Ali, 2013) on the top interest group that influence CSR, the finding of his study showed, interest group that includes employee, customers, government, media, institution, investors are among CSR influencer. He added an ethical stand point of the employee, their personal characteristics and belief have played vital role in adoption of CSR practice, Elijah L. Letangule, (2013) in his study to establish factors that affect CSR at Equity Bank LTD which included 430 respondents, he found that empowering employee to be interactive in leadership is determinant of CSR practice of the bank. The result provide a lesson for water bottlers and other stake holder of CSR practice that the goal of CSR practice can be achieved by educating, empowering, employee in to the CSR activities.

The second determinant of CSR is customer demand (CD). The finding showed, due to the consumer demand existence as a predictor in the model and increment by one unit, CSR practice is increased by a factor of 5.68 keeping other factors constant. Warsi Ali (2013) findings discussed under the labour pressure result also support that customers are also among the interest group that influence CSR practices. Another study in India designed to research driving factors of CSR conducted on 318 respondents, ranked ethical consumerism as $9^{\text {th }}$ order. The other factors like compliance of company, community present increasing social awareness, commercial pressure international standard need, domestic regulation public opinion, reputation are ranked from one to eight ranks. The difference in the result of both studies can be the personal characteristics of different cultures, customs, beliefs, family upgrading, race, religions, all affects the personal characters in determining CSR practices(Warsi Ali, 2013) It can be concluded, that customer demand is one of determinant of CSR activities that manufacturing firms consider customer are stakeholder who have high interest and high influencer of their organization.

Regarding the community pressure (CP), the SPSS result of the model indicated, because of the increment by one unit of community pressure $(\mathrm{CP})$ as a predictor, the dependent variable (CSR) practice, is increased by a multiple of 8.76 which is the highest of all score for $\operatorname{ExpB}$ value. This result is alarming as well as opportunity for companies if they invest on the community so that the companies injoy the benefit of CSR practices. Some of empherical studious that support this result includes Indian study that ranked driving force of CSR based on the perception of 318 respondents. The finding showed community pressure and philanthropy is ranked first and second followed by compliance of companies with regulations. Also empherical study conducted by ,Alejandra, etal (2016) in a public hospital on perception of 256 hospital workers support this result.The study of Alejandra, etal (2016) was based on guideline of ISO 26000, and the result of Aleandra, etal 2016 showed respect for consumer affairs, positive and active participation in community development are significantly determine CSR activities of the hospital. This finding also support customer demand (CD) find of the this study pervious result.

The inferential statistics result of SPSS in table 4.2 showed sustainability determinant such as environmental protection represented by (SU) received $0.15 \exp (\mathrm{B})$ value and $-1.93 \mathrm{~B}$ coefficient value significant at $\mathrm{P}<0.10$. the odd ratio less than one resulted a decreasing effect if it exists as the predictor variable. There for sustainability activity (SU) is not significant to perceive by the respondents involved in the study. The probability of the wald statistics ( $P$ value) for sustainability is gather than the level of significance $(0.10>0.05)$. Hence there is no enough evidence to reject the null hypothesis that $\exp (\mathrm{B})$ coefficient of $\mathrm{SU}$ is equal to zero.

The result indicated sustainability practice of the firm is not determinant of CSR practice for this case. Contrary to this result, multiple of theoretical findings support that sustainability practices such as environmental protection increased profitability and in turn profitability increased the CSR practice of organizations. But there are also few empherical evidence that support the result that environmental protection is not determinant of CSR practice. The study by Alejandra z. etal (2016) conducted on 256 public hospital respondents based on ISO 2600, supported this environmental protection as sustainability is not determinant of CSR. The finding by Alejandra, (2016), showed respect for consumer affairs active participation in community development significantly influence CSR activity of the organization. Respect for human right environmental protection and fair labour treatment are not significant determinant of CSR practice. The finding of Aleandre support some of the determinant like community pressure (CP), customer affairs and sustainability practices (SU) result of this study, but it didn't support labour practice and operating practices which are indicators of labor pressure treatment.

The final determinant of CSR in this model is social license to operate (SL) which has exp (B) coefficient of 3.31 and significant at $\mathrm{P}$ value $<0.01$. The finding indicateed the existence of social license and increment by one unit, increased the existence of CSR practice by a factor of 3.31 keeping other variables constant. The finding by Alexander k.(2014),conducted on 200 respondents on the CSR determinants perception, respondents rank rising of international standards, reputation need, domestic regulations, compliance to the regulation and public opinion are among that factors determined CSR practice. All the factors listed as determinant of CSR under Alexander K.(2014)are indicators of social license to operate. Hence the finding in supports the result of this researcher. 
Moreove, the findings of Adeyemo S.A Oyebamiji F.F(2014),conducted on Nigerian manufacturing firms under the topic "An Evaluation of factors Influencing Corporate Social Responsibility in Nigerian Manufacturing Companies"support the result of social licence as determinant of CCSR and Other Results like consumer demand(CD) andlabour Pressure (LP).The result of their study identified, factors that influenced CSR practices are competition, employees demand, government policy, organizational culture, and customer demand.

\section{Conclusion and Recommendation 5.1 Conclusion}

The topic of CSR has received much attention because, there has been a growing public awareness of the role of corporations in society. This increased attention is also likely because of the promise of increased demands of internal and external stakeholders of the organizations such as the employee, customer, and the community. As Ramanathan et al. (2014) discussed internal and external stakeholder's pressures of a firm, economic pressures, environmental regulations, and pressures of environmental compliance have affected environmental performance of firms. Therefore it is important to expand the CSR research towards the drivers of CSR in order to further understand the construct.

With major focus on Stakeholders theory, this study supports multiple drivers of CSR theoretical and empirical findings to answer the following research's leading objective: Assess the determinants of corporate social responsibility in Mineral water bottling companies in Dire Dawa Administration.

According to the data interpretation scale designed for the study, the mean score 3.51 and above shows agreement, the mean score from 2.51 to 3.50 shows neutrality and mean score below 2.50 shows disagreement perception of the respondents. By observing the composite mean score of CSR predictors construct, the maximum score was 3.33 followed by $3.30,3.12,3.03$ and 2.71 for labour pressure treatment, social license, customer demand treatment, community demand treatment, sustainability practice CSR and Social licence CSR practice dimension of water bottler companies.

One of the research objective was to find out the extent of CSR practices in mineral water companies under the study. The results of descriptive analysis showed, CSR practice of water bottlers is fall under the scale between 2.51 to 3.50 ranges. It showed respondents are neutral to perceive the CSR practice of companies or respondents are refraining from giving their perception towards CSR practice regarding water bottlers in Dire Dawa Administration. From the understanding of Ethiopian society's culture and norm, the researcher concluded that neutrality perception of the respondent, between 2.51 to 3.50 ranges, is approaching to disagreement towards company's CSR practice. Therefore respondents disagree that water bottling companies are doing well in discharging their corporate social responsibility. The result is clear evidence that the extent of CSR practice of those companies is very low.

The other objective of the study is to find out challenges that impedes from practicing CSR in water bottling companies in Dire Dawa Administration.It can be understood from perception fro respondents, there poor channel of communication with customers and other stakeholders because of far company site and other unexplained reasons. Thire communication channel is active to some extent with whole sallers but not with final consumer of their products. In order to respond the community need there should be regular dialogue with community and understand the norm and culture of the society.In this regard the find shows poor practice for these companies. The descriptive result depicts companies must have well organized office and warehouse at the center of the city, roads and other infrastructure has to lead to those water bottlers site. All stake holders around the chair includes water bottlers companies, government office such as municipality office, TIIA, EFAPA, the city council are not doing in coordination as per the information from EFAPA discussed under sustainability. Accordingly, the very limited involvement of EFAPA in the environmental matters, lack of coordination with the city beautification agency are some challenges in practicing CSR. All these findings witnessed those challenges hinder the practice of CSR in mineral water bottling companies in Dire Dawa administration.

The research tried also to access the extent to which stakeholders are working together to achieve better practice of CSR. An empherical study in Nigerian bank sector regarding the influence of CSR in the bank industry finds that, even though $60 \%$ of the banks CSR practice is voluntary action by the bank, $40 \%$ of the CSR practices of the bank is because of the pressure from government, NGOs, and influence groups like media. According to the interview with four organization namely; TIIA,PCESSA,EFAPA and DDBA their action towards CSR is not coordinated. TIIA seems very happy to receive investment request from water bottlers with inconsistence goal of EFAPA that see extra water bottling company after words in Dire Dawa is threat for the environment and echo system. The beautification agency of the city is organizing the public youth to recycle the plastic bottles without coordination with bottler companies including Coca-Cola Company one of plastic bottle contributors for the environment. The work of PCESSA regarding labour treatment is limited to its office. Moreover, except the Environmental impact assessment report at the beginning of license process, no responsible body follows and checks the production process of firms towards policies and regulations. All these findings showed stakeholders are no working in coordination towards efficient companies CSR practice. CSR theory points out that organizations 
continually seek to ensure that they operate within culture and norms of their respective societies to retain positive relation between society and the organization (Dowling \& Pfeffer, 1975; Deegan, 2002; and Frynas \& Yamahaki, 2016) According to the literature review collected in under the empherical findings of CSR the expectation of society from business firm increased in recent years. From the data analysis for community welfare and social license to operate in the society, respondents think companies did not practice to the extent that they agree the practice. Unless companies increase their practice of CSR in order to get social license from community, they are threatened for their operation.

\subsection{Recommendations}

The practice of CSR will be continuing the front line issue of all organizations. Based on the conclusion of the research, this topic discussed recommendations applicable for all stake holders, business organization, governmental, NGOs and civic society.

The study showed labour pressure, customer demand, community pressure, social license to operate are determinants of CSR. The result showed the extent of CSR practice in mineral water bottlers is at its low level. There are challenges for water bottling company to practice CSR emerged from the internal and external stake holders. In addition, stake holder of CSR practice lacks co-ordination towards CSR practice. Based on these findings the following recommendations are forwarded.

Mineral water bottling companies should develop and integrate CSR practice with their strategic plan and establish commitment to practice it towards the community, the employee, the customer and the environment.

The distribution channel of water bottling company products goes from the producer to whole seller and then to the consumer. Producers should reach the final consumer in order to improve the low perceived customer demand by the study. In order to solve the gap, Water bottling companies should have well organized offices that serve the customers and the final consumer at the downtown of the city. The government also has to furnish the infrastructure like better road leads to the far location of water manufactures site relative to the city.

Dire Dawa and the road sides leading to the city is becoming the land fill of plastic bottles thrown away after usage. This fact is supported by the research while interview with managers. The result is parallel with the current global environmental reports on workshops and media coverage. Without the active participation of the polluters (in our case water bottling companies), and influence group such as community, media and the government, the regulators the problem will goes from bad to worse. Stake holders like the polluter, regulators, government bodies, media, and activist work to gather to improve the practice of CSR. Specifically the city investment office (TIIA), the environmental agency (EFAPA), the city municipality office should set Common goal with mineral water bottlers concerning CSR practice and work towards it.

It is advantageous for firms with in the same industry works together on common goals. TedlaZegey (2013), during his study on CSR practice of horticultures around Addis Ababa, he found out that horticulture industries developed and practiced code of good production practice that governs all horticulture. The code is developed by their association EHPEA. There for mineral water companies can organize themselves in to association and works towards their common goal. They can also use the public media for common goal like public awareness creation, develop and launch joint community based projects etc. Rehabilitation of garbage site, recycling projects of the plastic bottles are also some of the common goals water bottling companies can do jointly one on other.

Even though CSR is a voluntary activity, compliance with local and international policies, develop code of the industry practice, is part of CSR practice. Therefore, pressure of regulators is necessary to check whether this water bottling companies follow policies and regulation concerning labour treatment, environment, human right, etc.

CSR practice is adynamic concept applied for every organization in this contemporary world. In order to support the practice of CSR with human power, higher educational institution should in clued CSR as a major discipline

\section{REFERENCE}

Angeloantonio R \& Francesco P (2014), Investigating Stakeholder Theory and Social Capital: CSR in Large Firms and SMEs (Springer Netherlands).

Antonia A. and vonWeltzein H. (2009), CSR: One Size does not Fit All, IESE Business School University of Navarna

Anupam S. and Ravi K. (2012), Corporate Social Responsibility Initiatives of Major Companies of India with Focus on Health, Education and Environment, African Journal of Basic \& Applied Sciences, IDOSI Publications

Arctic council, (2004) Arctic Climate Impact Assesment.www.wbcsd.org.

Armstrong Michael (2008) 8th edition a handbook of HRM practice preteville Road London

Artiach, T., Lee, D., Nelson, D., \& Walker, J. (2010). The determinants of corporate sustainability performance. Accounting \& Finance, 50 
Australian Government (2010), Social Responsibility in the Mining and Metals Sector in Developing Countries

Blyth (2005) Business having responsible director vol 59

Bonefeld-Jørgensen EC, Long M, Hofmeister MV, Vinggaard AM. 2007. Endocrine-disrupting potential of bisphenol A

Bowen, H.R. (1990) Social Responsibilities of the businessman, Harper \& Brothers.NewYork. USA

Brammer, S., Millington, A., \& Rayton, B. (2007). The contribution of corporate social responsibility to organizational commitment. The International Journal of Human Resource Management, 18(10), 1701-1719

Carrott, (1990) Ethical dimension of international management, sage publication, Inc, New York

Commission of the European Communities (2012), Corporate Social Responsibility, Main Issue, The European business network for CSR

Curran M. (2005), Assessing the Rate of Return of the Adoption of Corporate Social Responsibility Initiatives, University of Edinburgh Dane

Deegan, C. (2002). Introduction: the legitimising effect of social and environmental disclosures-a theoretical foundation. Accounting, Auditing \& Accountability Journa

Dowling, J., \& Pfeffer, J. (1975). Organizational legitimacy: Social values and organizational behavior. Pacific Sociological Review,

Freeman, (1984) Corporate strategy and the search for ethic, prentice hall publishing company . 9.Fredric, W.C (1992) Business and society corporate strategy, public policy ethics, New York

Friedman M. (1970), The Social Responsibility of Business is to Increase its Profits, New York Times Magazine

Gamerschlag, R., Möller, K., \& Verbeeten, F. (2011). Determinants of voluntary CSR disclosure: empirical evidence from Germany. Review of Managerial Science,

Ghoshal, S. \& Moran, P. (1996). Bad for practice: A critique of the transaction cost theory. Academy of Management, 21: 13-47.

Global Future (2004) National Intelligence Council, www.cia.gov.

Hadi C. and Raveed K. (2011), Iranian Corporations and Corporate Social Responsibility: An Overview to Adoption of CSR Themes, SAGE

Hafsi, T., \& Turgut, G. (2013). Boardroom diversity and its effect on social performance: Conceptualization and empirical evidence. Journal of Business Ethics, 112(

Harjoto, M., \& Laksmana, I. (2016). The Impact of Corporate Social Responsibility on Risk Taking and Firm Value. Journal of Business Ethics, 1-21.

Hopkins M. (2011), A Planetary Bargain: Corporate Social Responsibility Comes of Age (Macmillan, UK, 1998) Updated by author July 2011 (point 4 based upon suggestion by Nadine Hawa, student in my class at University of Geneva)

http://mallenbaker.net/article/clear-reflection/definitions-of-corporate-social-responsibility-what-is-csr) visited on $20 / 07 / 2018$

http://www.mining.com/ethiopia-suspends-midroc-gold-mining-license-weeks-protests/

https:/www.acowtancy.com/textbook/acca-f1/a2-stakeholders-in-business-organisations/the-mendelowframework/notes(July 19,2018 Accesed

John Gerard Ruggie and Kytle, Beth. 2005. "Corporate Social Responsibility as Risk Management: A Model for Multinationals."Corporate Social Responsibility Initiative Working Paper No. 10 Ramanathan, R., Poomkaew, B., \& Nath, P. (2014). The impact of organizational pressures on environmental performance of firms. Business Ethics: A European Review

John O., Sastry G. and David A. (1995), Applied Regression Analysis: A Research Tool, Second Edition, North Carolina State University Keith

Kassaye Deyassa.(2016) 'CSR From Ethiopian Perspective' international journal of scientific \& technology research volume 5, issue 04, pp 299-329

Kiarie, E.K. (1997) Attitude \& Awareness of executive of medium scale manufacturing firms in Nairobi, Unpublished University of Nairobi MBA project.

Makiwala, (2010) Argument for and against CSR March 10th 2011 14:12:19am.

Mallen B. (2012), Corporate Social Responsibility, Health and Safety - reframed as a term of abuse, mallenbaker.net

Marano, V., \& Kostova, T. (2016). Unpacking the institutional complexity in adoption of CSR practices in multinational enterprises. Journal of Management Studies, 53(1), 28-54

Martin S. and Yunita A. (2012), Impact of Corporate Social Responsibility toward Firm Value and Profitability, BINUS University, Jakarta, Indonesia

Mathias Nigatu BIMIR(2016) Corporate Social Responsobility (CSR) in the Ethiopian Banking Sector: A Case Study on Commercial Bank of Ethiopia (CBE) ,Nile Journal of Business and Economics ,vol 7(2)

Matthias H. and Ludwig T. (2009), Corporate Social Responsibility in Agribusiness: Empirical Findings from Germany, University of Goettingen, Germany 
Miles, R.H. (1998) Managing the Corporate Social Environment, Englewood Cliff New Jersey: Prentice-Hall Inc

Mitchell, R. K., Agle, B. R., \& Wood, D. J. (1997). Toward a theory of stakeholder identification and salience: Defining the principle of who and what really counts. Academy of Management Review, 22(4

Mory, L., Wirtz, B. W., \& Göttel, V. (2016). Factors of internal corporate social responsibility and the effect on organizational commitment. The International Journal of Human Resource Management, 27(13), (M. Katarzyna and P. Zaborek, 2015) Does Business Model Affect CSR Involvement? A Survey of Polish Manufacturing and Service Companies

Moses and Benham (2004) CSR belongs with HR Canadian HR reporter, vol 17 no.7

Moses and Benham (2005) CSR belongs with HR Canadian HR reporter, vol 17 no.19

Mothy F. Slaper (2011), the Triple Bottom Line: What Is It and How Does It, Work?

Mududa (2003) An investigation of the social Responsibility practices among polythene manufacturers in Kenya. Unpublished Kenyatta University MBA project.

Nirmala L. (2008), the Social and Environmental Impacts of Leather Production, Presentation Transcript

Padgett, R. C., \& Galan, J. I. (2010). The effect of R\&D intensity on corporate social responsibility. Journal of Business Ethics, 93(3), 407-418.

Park, B. I., \& Ghauri, P. N. (2015). Determinants influencing CSR practices in small and medium sized MNE subsidiaries: A stakeholder perspective. Journal of World Business

Paul H. (2007), Corporate Social Responsibility an Implementation Guide for Business, International Institute for Sustainable Development

Peerce (2000) Strategic management formulation implementation and control: 7th edition Mc Graco Hill Tnt pg 53

Pirsch, J., Gupta, S., \& Grau, S. L. (2007). A Framework for Understanding Corporate Social Responsibility Programs as a Continuum: An Exploratory Study. Journal of Business Ethic. 70(2): 125-140

Reverte, C. (2009). Determinants of corporate social responsibility disclosure ratings by Spanish listed firms. Journal of Business Ethics, 88(2), 351-366.

Ronald Bown,(2006) President, Chilean Fruit Exporters Association (at GRI G3 launch, October 2006

Samaha K., Dahawy K. ,and Hussainey, K. (2011). 'Corporate governance voluntary disclosures incentives in Egypt', Working paper, American University in Cairo, Egypt.Cited in khaled hussainey.(2012) factors affecting corporate social responsibility disclosure in egpt Stirling University, Uk

Shafiqur R. (2011), Evaluation of Definitions: Ten Dimensions of Corporate Social Responsibility, World Review of Business Research Vol. 1.

Stefan Bruns ( 2017) The determinants of corporate social responsibility: empirical evidence from the Netherlands University of Twente Business Administrations

Suchman, M. C. (1995). Managing legitimacy: Strategic and institutional approaches. Academy of Management Review, 20(3), 571-610.

Swift, Tracey and Zadek, Simon (2002). Corporate social responsibility and the competitive advantage of nations.

Tallontire, A. \& Greenhalgh, P. (2005), Establishing CSR Drivers in Agribusiness, Final Report for Foreign Investment Advisory Service International Finance Corporation and World Bank

Tedla Zegeye (2013). corporate social responsibility practice in ethiopian floricultural industry

Tompkins, (2003) "The business case for CSR" where are we? International Journal for business performance management vole "s no.2, 3, pp

Ufadhili Trust Kenya, (2010) Promoting CSR in Kenya, www.ufadhilitrust.org

Vaaland T., Heide M. and Gronhaug K. (2008), Corporate Social Responsibility: Investigating Theory and Research in the Marketing Context, European Journal of Marketing Responsibility, World Review of Business Research Vol. 1.

William F. and Jose C. (2009), Three Views of Corporate Social Responsibility Hopkins M. (2003), The Planetary Bargain: Corporate Social Responsibility Matters Earth scan Publications Ltd.: London

William F. and Jose C. (2009), Three Views of Corporate Social Responsibility

William, R. (2010), Tools, Techniques \& Approaches for sustainability: Collected writings in environmental assessment policy and management, World Scientific publishing Co. pte. Ltd

WilliamG.Zikmund,BarryJ.Babin,JonC.Carr,MitchGriffin(1998)BusinessResearch_Methods,_8th_EditionSouth-Western_Colle

Windsor, (2001) Future of CSR international journal of organization analysis vol 9 pp 22-56.

World Bank,(2004) Environmental Matters www.worldbank .org

World Business Council,(2004) Making Good Business Sense, www.wbcsd.org. 